\title{
GRK1-Dependent Phosphorylation of S and M Opsins and Their Binding to Cone Arrestin during Cone Phototransduction in the Mouse Retina
}

\author{
Xuemei Zhu, ${ }^{1}$ Bruce Brown, ${ }^{1}$ Aimin Li, ${ }^{1}$ Alan J. Mears, ${ }^{2,3}$ Anand Swaroop, ${ }^{2,3}$ and Cheryl M. Craft ${ }^{1}$ \\ ${ }^{1}$ The Mary D. Allen Laboratory for Vision Research, Doheny Eye Institute, Department of Cell and Neurobiology, the Keck School of Medicine of the \\ University of Southern California, Los Angeles, California 90089-9112, and Departments of ${ }^{2}$ Ophthalmology and Visual Sciences and ${ }^{3}$ Human Genetics, \\ University of Michigan, Ann Arbor, Michigan 48105
}

\begin{abstract}
The shutoff mechanisms of the rod visual transduction cascade involve G-protein-coupled receptor (GPCR) kinase 1 (GRK1) phosphorylation of light-activated rhodopsin $\left(\mathrm{R}^{\star}\right)$ followed by rod arrestin binding. Deactivation of the cone phototransduction cascade in the mammalian retina is delineated poorly. In this study we sought to explore the potential mechanisms underlying the quenching of the phototransduction cascade in cone photoreceptors by using mouse models lacking rods and/or GRK1. Using the "pure-cone" retinas of the neural retina leucine zipper ( $\mathrm{Nrl}$ ) knock-out $\left(\mathrm{KO}^{-1-}\right)$ mice (Mears et al., 2001), we have demonstrated the light-dependent, multi-site phosphorylation of both $S$ and $M$ cone opsins by in situ phosphorylation and isoelectric focusing. Immunoprecipitation with affinitypurified polyclonal antibodies against either mouse cone arrestin (mCAR) or mouse $S$ and $\mathrm{M}$ cone opsins revealed specific binding of mCAR to light-activated, phosphorylated cone opsins. To elucidate the potential role of GRK1 in cone opsin phosphorylation, we created $\mathrm{Nrl}$ and Grk1 double knock-out $\left(\mathrm{Nrl}^{-I-} \mathrm{Grk}^{-I-}\right.$ ) mice by crossing the $\mathrm{Nrl}^{-I-}$ mice with Grk1 ${ }^{-I-}$ mice (Chen et al., 1999). We found that, in the retina of these mice, the light-activated cone opsins were neither phosphorylated nor bound with mCAR. Our results demonstrate, for the first time in a mammalian species, that cone opsins are phosphorylated and that CAR binds to phosphorylated cone opsins after light activation.
\end{abstract}

Key words: cone opsin; phosphorylation; cone arrestin; phototransduction; coimmunoprecipitation; mouse retina

\section{Introduction}

Phototransduction mechanisms are well documented in rod photoreceptors and now are regarded as a classic model system of G-protein-coupled receptor (GPCR) signaling (Baylor, 1996; Leskov et al., 2000; Fain et al., 2001). The phototransduction cascade in cone photoreceptors is thought to be similar to that of rods because rod homologs of phototransduction components are expressed in cones. Nevertheless, the kinetics of photoresponse in the two photoreceptor types are different. Cones are several hundred-fold less sensitive to light than are rods (Pugh and Lamb, 2000), and yet they recover sensitivity much faster

Received Jan. 16, 2003; revised May 20, 2003; accepted May 23, 2003.

These studies were supported, in part, by National Institutes of Health/National Eye Institute Grants EY00395 (R.N.L. and C.M.C.) and EY11115 (A.S.), grants from Core Vision Research Center (EY03040 to Doheny Eye Institute and EY07003 to University of Michigan), the Smith Endowment for Neurogenetic Research, the Foundation Fighting Blindness, and Research to Prevent Blindness. Postdoctoral support was provided by generous contributions from the Tony Gray Foundation and Dorie and Fred Miller. C.M.C. is the Mary D. Allen Chair for Vision Research, Doheny Eye Institute. We thank Dr. Ching-Kang Chen for providing the Grk $1^{-1-}$ mice for our studies. We also thank Drs. Jeannie Chen, Anna Mendez, and Angela Roca for helpful suggestions on the phosphorylation experiments and for critical reading of this manuscript.

This manuscript is dedicated to Mary D. Allen for her generous support of our program in vision research and Dr. Richard N. Lolley, our lifetime collaborator.

Correspondence should be addressed to Dr. Cheryl M. Craft, Mary D. Allen Chair for Vision Research, Doheny Eye Institute, Professor and Chair, Department of Cell and Neurobiology, The Keck School of Medicine of the University of Southern California, 1333 San Pablo Street, BMT 401, Los Angeles, CA 90033. E-mail: ccraft@usc.edu.

Copyright $\odot 2003$ Society for Neuroscience $\quad$ 0270-6474/03/236152-09\$15.00/0 than rods after light flashes that generate similar membrane currents (Baylor et al., 1979; Perry and McNaughton, 1991).

In rod photoreceptors the timely deactivation of photoactivated rhodopsin $\left(\mathrm{R}^{*}\right)$ by GPCR kinase 1 (GRK1)-mediated $\mathrm{R}^{*}$ phosphorylation followed by rod arrestin binding is critical for effective rod vision (Wilden et al., 1986a; Baylor and Burns, 1998). The low abundance of cones in most mammalian retinas has made it difficult to elucidate directly the biochemical and molecular mechanisms underlying cone phototransduction. It has been suggested that cones may rely primarily on regeneration for inactivation of photolyzed visual pigments, because patients with Grk1 null mutation have either normal or only slightly abnormal photopic vision (Cideciyan et al., 1998). However, mouse retinas lacking GRK1 expression display profoundly slowed recovery of cone photoresponses, suggesting that GRK1-dependent opsin phosphorylation may be involved in the shutoff of cone phototransduction in the mammalian retina (Lyubarsky et al., 2000). Identification of a cone-specific GRK7 (Hisatomi et al., 1998; Weiss et al., 1998, 2001; Chen et al., 2001) and cone arrestin (CAR) (Murakami et al., 1993; Craft et al., 1994; Craft and Whitmore, 1995; Hisatomi et al., 1997; Maeda et al., 2000; Smith et al., 2000; Zhu et al., 2002a,b) further supports the hypothesis that similar shutoff mechanisms exist in cone photoreceptors.

In this study we provide direct biochemical evidence of cone opsin phosphorylation and CAR binding to phosphorylated cone 
opsins during phototransduction, using the neural retina leucine zipper ( $\mathrm{Nrl})$ knock-out $\left(\mathrm{KO},{ }^{-1-}\right)$ mice (Mears et al., 2001). NRL, a transcription factor of the basic motif leucine zipper family, is expressed preferentially in rod photoreceptors (Swaroop et al., 1992; Swain et al., 2001) and implicated in rod-specific gene regulation (Rehemtulla et al., 1996; Bessant et al., 1999) and photoreceptor differentiation (Mears et al., 2001). The analysis of the $\mathrm{Nrl}^{-1-}$ retinas revealed a complete lack of rod function and rodspecific gene expression, with a concomitant increase in S-cone function and cone-specific gene expression, including $S$ opsin, cone transducin, and CAR (Mears et al., 2001). Therefore, the photoreceptors of the $\mathrm{Nrl}^{-/-}$mouse retina are functionally and biochemically cones, although they are proposed to be cone-rod intermediates because of their abnormal morphology.

Using the pure-cone retinas of the $\mathrm{Nrl}^{-1-}$ mice, we demonstrate that both $\mathrm{S}$ and $\mathrm{M}$ cone opsins are phosphorylated after light exposure and that CAR selectively binds to light-activated, phosphorylated cone opsins. We also created Nrl and Grk1 double $\mathrm{KO}\left(\mathrm{Nrl}^{-1-} \mathrm{Grkl}^{-/-}\right)$mice by crossing the $\mathrm{Nrl}^{-/-}$with the Grk1 ${ }^{-1-}$ mice (Chen et al., 1999; Lyubarsky et al., 2000) and show that, in these double $\mathrm{KO}$ mice, neither S nor M opsin is phosphorylated either in light or in darkness, nor does CAR bind to the light-activated cone opsins, suggesting that GRK1 is responsible for cone opsin phosphorylation during phototransduction in the mouse retina.

\section{Materials and Methods}

Animals. C57BL/6J mice were purchased originally from the Jackson Laboratories (Bar Harbor, ME). The $\mathrm{Nrl}^{-1-}$ (Mears et al., 2001) and Grk1 ${ }^{-1-}$ mice (Chen et al., 1999; Lyubarsky et al., 2000) were described previously. To generate $\mathrm{Nrl}^{-1-} \mathrm{Grk}^{-1-}$ double $\mathrm{KO}$ mice, we bred the $\mathrm{Nrl}^{-1-}$ mice with the Grk1 ${ }^{-1-}$ mice. After two rounds of breeding, mice homozygous null $\left({ }^{-1-}\right)$ for Nrl were identified by Southern blot analysis as previously described (Mears et al., 2001), and mice null for Grk1 were identified by genomic PCR, using primers specific for the Grk1 wild type (WT) or for the Grk1 KO construct. The WT and $\mathrm{Nrl}^{-1-}$ mice were reared under a $12 \mathrm{hr}$ light/dark cycle, and the Grk1 ${ }^{-1-}$ and the $\mathrm{Nrl}^{-1-} \mathrm{Grk}^{-1-}$ double KO mice were reared in total darkness.

Antisera generation. Rabbit antisera against the peptides of mouse S opsin (residues 1-11, MSGEDDFYLFQ) and M opsin (residues 3-16, QRLTGEQTLDHYED) were made for our research project by Zymed Laboratories (South San Francisco, CA) and affinity-purified against the peptides with the SulfoLink kit (Pierce, Rockford, IL) as previously described (Zhu and Craft, 2000).

Immunoblot analysis. Total retinal homogenates from normal C57 mice were used for immunoblot analysis with either anti-S or anti-M opsin antibody and HRP-conjugated anti-rabbit secondary antibody and were visualized by an enhanced chemiluminescence (ECL) kit (Amersham Biosciences, Arlington Heights, IL) (Craft et al., 1998).

Immunohistochemistry. The protocol for immunohistochemistry on mouse retinal sections has been published previously (Zhu et al., 2002b). For cone opsin antibody characterization the sections were incubated with either the anti-M or anti-S opsin peptide polyclonal antibody, followed by incubation with a fluorescein anti-rabbit IgG. To visualize all cones, we incubated the slides with biotinylated peanut agglutinin (PNA; Vector Laboratories, Burlingame, CA) for $1 \mathrm{hr}$ at room temperature (RT) and then with Texas Red-avidin D (Vector Laboratories) for $1 \mathrm{hr}$ at RT. After washing, the slides were coverslipped and photographed.

For immunofluorescent triple labeling, the retinal sections were incubated with sequential primary antibodies, including a rabbit polyclonal [anti-M opsin, anti-S opsin, or anti-mCAR LUMIJ (Zhu et al., 2002b)] and a mouse monoclonal antibody [GRK1-specific D11 (Zhao et al., 1998; Chen et al., 2001; Weiss et al., 2001), Affinity BioReagents, Golden, $\mathrm{CO}$ ] at 1:1000 and 1:200 dilutions, respectively. After the washing steps the sections were reacted with a mixture of AMCA-anti-rabbit IgG (1: $100)$ and fluorescein anti-mouse IgG (1:100; both from Vector Labora- tories) for $1 \mathrm{hr}$ in the dark at RT. After thorough rinses with PBS containing $0.1 \%$ Triton $\mathrm{X}-100$, the sections were stained with propidium iodide (PI; $1 \mu \mathrm{g} / \mathrm{ml}$ ) for $15 \mathrm{~min}$ at RT to visualize all nuclei.

For retinal whole mounts a lens-attached retina was dissected from the sclera, choroid, and pigment epithelium and was fixed in $4 \%$ paraformaldehyde in PBS overnight on a rotator at $4^{\circ} \mathrm{C}$. Tissues then were washed three times and subjected to double-immunofluorescent staining. After blocking, the retinas were incubated with the first primary antibody (either an anti-S opsin or anti-M opsin polyclonal antibody) at 1:1000 dilution and then reacted with a fluorescein anti-rabbit IgG. Because the second primary antibody was also from rabbit, a microwave method (Tornehave et al., 2000) was performed to prevent cross-reaction with subsequently applied reagents. After the microwave treatment a second primary antibody (anti-mCAR polyclonal antibody LUMIJ) (Zhu et al., 2002b) was added, followed by a Texas Red anti-rabbit IgG. Finally, lenses were removed from retinas, and small cuts were made in the retinas to facilitate flat mounting on slides, with the photoreceptor side up.

Detection of soluble and membrane-bound mCAR. WT and Grk $1^{-1-}$ mice were killed either mid-day under room light (after light exposure for at least $2 \mathrm{hr}$ ) or dark-adapted overnight and killed in the dark under infrared (IR) light. Both retinas from the same mouse were homogenized gently (not sonicated) in $125 \mu$ l of $50 \mathrm{~mm}$ sodium phosphate buffer, $\mathrm{pH}$ 6.8 , either under room light or under IR light. Retinal homogenates were centrifuged at 13,000 rpm in a refrigerated microfuge either in the light or in the dark for $10 \mathrm{~min}$ at $4^{\circ} \mathrm{C}$. The supernatants were removed immediately, the pellets were resuspended and homogenized in $125 \mu \mathrm{l}$ of buffer, and all samples were treated with SDS sample buffer either in the light or dark. An equal volume of proteins was resolved on replicate $11.5 \%$ SDSPAGE gels and transferred to polyvinylidene difluoride (PVDF) membranes (Immobilon, Millipore, Bedford, MA), which were incubated in either a polyclonal mCAR (LUMIJ) (Zhu et al., 2002b) or a monoclonal rod arrestin/S-antigen (SAG) antibody (C10C10; kindly provided by Dr. Larry A. Donoso, Wills Eye Research Hospital, Philadelphia, PA). The experiment was repeated at least three times, and the immunoreactive bands were quantitated by using ImageQuant software (Molecular Dynamics, Sunnyvale, CA) after the film was scanned.

In situ phosphorylation of opsins in mouse retinas. Adult $\mathrm{WT}, \mathrm{Nrl}^{-1-}$, and $\mathrm{Nrl}^{-I-} \mathrm{Grk}^{-I-}$ mice were dark-adapted overnight and killed in the dark. The retinas were dissected under IR light; each was put into $0.5 \mathrm{ml}$ of phosphate-free Krebs' buffer [consisting of (in mM): 100 HEPES, pH 7.4, 10 glucose, $120 \mathrm{NaCl}, 5 \mathrm{KCl}, 1 \mathrm{MgSO}_{4}, 1 \mathrm{CaCl}_{2}$ ] containing $0.6 \mathrm{mCi}$ $(1.25 \mathrm{mCi} / \mathrm{ml}){ }^{32} \mathrm{P}$ orthophosphate and was incubated for $30 \mathrm{~min}$ at $\mathrm{RT}$ in the dark. The buffer was changed to nonradioactive Krebs', and one retina of each strain was homogenized in SDS sample buffer in the dark while the other retina was exposed to direct bright sunlight, which is $\sim 8000$ foot candle ( $\mathrm{fc}$ ), for $10 \mathrm{~min}$ before homogenization. The proteins were resolved on an $11.5 \%$ SDS-PAGE gel and transferred to a PVDF membrane. The membrane was exposed first to a Storm PhosphorImager screen (Molecular Dynamics) to observe opsin phosphorylation, followed by incubation in antibodies to mouse $\mathrm{M}$ opsin, $\mathrm{S}$ opsin, or rhodopsin (1D4) to observe the quantity and location of each opsin relative to the radioactive phosphate $\left({ }^{32} \mathrm{P}\right)$.

Separation of phosphorylated opsin species by isoelectric focusing. Two $\mathrm{Nrl}^{-1-}$ (20-23 weeks old) and two age-matched WT mice were darkadapted overnight. The mice were killed, and the retinas were dissected under IR light. Two retinas from each strain were exposed on ice to direct bright sunlight $(\sim 8000 \mathrm{fc})$ for $10 \mathrm{~min}$ while two retinas were kept in the dark. The retinas were frozen immediately on dry ice, thawed, and homogenized in $0.5 \mathrm{ml} /$ retina of homogenization buffer containing (in mм) 10 HEPES, pH 7.5, $140 \mathrm{NaCl}, 1 \mathrm{MgCl}_{2}, 0.6$ EDTA, $50 \mathrm{NaF}$, and 5 adenosine plus $2 \% \mathrm{BSA}, 100 \mu \mathrm{M}$ 11-cis-retinal, and protease inhibitors (500 $\mu \mathrm{M}$ 4-[2-aminoethyl]-benzene sulphonyl fluoride hydrochloride, $150 \mathrm{~nm}$ aprotinin, $1 \mu \mathrm{M} \mathrm{E}-64$, and $1 \mu \mathrm{M}$ leupeptin). The homogenates were rotated in the dark at $4^{\circ} \mathrm{C}$ for $45 \mathrm{~min}$, followed by centrifugation in the dark at $13,000 \mathrm{rpm}, 4^{\circ} \mathrm{C}$, for $30 \mathrm{~min}$ in a refrigerated microfuge. The membrane fractions, which were resuspended in $70 \mu \mathrm{l} /$ retina of buffer containing (in mM) 10 HEPES, pH 7.5, $1 \mathrm{MgCl}_{2}, 10 \mathrm{NaCl}$, and 0.1 EDTA plus $1 \%$ dodecyl maltoside and $100 \mu \mathrm{M} 11$-cis-retinal, were allowed to solubilize for $1 \mathrm{hr}$ by rotating at $4^{\circ} \mathrm{C}$ in the dark and were centrifuged 
$\left(13,000 \mathrm{rpm}, 4^{\circ} \mathrm{C}, 30 \mathrm{~min}\right)$; the supernatants were taken for isoelectric focusing (IEF) gels. Seven microliters (one-tenth of a retina) of each sample were applied to a $1 \mathrm{~mm}$ IEF gel containing 5\% Ready Mix IEF acrylamide (Amersham Biosciences), 6.3\% pH 3-10 ampholytes (Amersham Biosciences), $13.3 \%$ glycerol, and $0.5 \%$ dodecyl maltoside. The samples were applied $4 \mathrm{~cm}$ from the cathode of a $13 \mathrm{~cm}$ gel with $1 \mathrm{M}$ $\mathrm{NaOH}$ and $1 \mathrm{~m}$ phosphoric acid as the cathode and anode buffers, respectively. The gel was electrophoresed at $2500 \mathrm{~V}, 150 \mathrm{~mA}, 23 \mathrm{~W}$ for $2 \mathrm{hr}$ at $10^{\circ} \mathrm{C}$ on a flat-bed IEF apparatus (LKB-Wallac, Gaithersburg, MD). The gel was preelectrophoresed for $30 \mathrm{~min}$ before the samples were applied. After electrophoresis the proteins were transferred to a PVDF membrane and probed with antibodies to $\mathrm{S}$ opsin, $\mathrm{M}$ opsin, or rhodopsin.

Immunoprecipitation. Four adult $\mathrm{Nrl}^{-1-}$ or $\mathrm{Nrl}^{-1-} \mathrm{Grk}^{-1-}$ mice were dark-adapted overnight and killed; the retinas were dissected under IR light. The eight retinas were put into two tubes ( 4 retinas each) labeled dark and light, each containing $0.5 \mathrm{ml}$ of phosphate-free Krebs' buffer containing $0.6 \mathrm{mCi}{ }^{32} \mathrm{P}$ orthophosphate, and were incubated at RT for 30 $\mathrm{min}$. The retinas were washed and put in $1 \mathrm{ml}$ of Krebs' buffer lacking the ${ }^{32} \mathrm{P}$ orthophosphate. The light tube was uncapped and exposed to direct bright sunlight $(\sim 8000 \mathrm{fc})$ for $10 \mathrm{~min}$ on ice while the dark tube remained in the dark. The retinas were homogenized in $0.5 \mathrm{ml}$ of lysis buffer (50 mu Tris, pH 7.2, $150 \mathrm{~mm} \mathrm{NaCl}, 1 \%$ Triton X-100) containing protease inhibitors and $1.24 \mu \mathrm{M}$ okadaic acid (a phosphatase inhibitor) and were centrifuged at $13,000 \mathrm{rpm}, 4^{\circ} \mathrm{C}$, for $10 \mathrm{~min}$ to remove cell debris.

Immunoprecipitation (IP) was performed with the Protein A-Agarose IP kit (KPL, Gaithersburg, MD). Four hundred microliters of the retinal supernatants (dark or light) were mixed with $400 \mu \mathrm{l}$ of a $50 \%$ suspension of protein A-agarose in lysis buffer with no protease inhibitors or okadaic acid and rotated at $4^{\circ} \mathrm{C}$ for $1 \mathrm{hr}$ to preclear the samples (remove proteins from the lysates that bind nonspecifically to the resin). The samples were centrifuged at $14,000 \times g$ for $20 \mathrm{sec}$, and the agarose pellet was discarded. The precleared dark or light supernatant $(150 \mu \mathrm{l})$ was mixed with $5 \mu \mathrm{g}$ of affinity-purified polyclonal antibodies against mCAR, S opsin, M opsin, or CRX (control) and was incubated with end-over-end mixing overnight at $4^{\circ} \mathrm{C}$. Fifty microliters of a $50 \%$ suspension of protein A-agarose in lysis buffer with no protease inhibitors or okadaic acid were added, and the tubes were rotated in the dark for $1.5 \mathrm{hr}$ at $4^{\circ} \mathrm{C}$. The immunoprecipitates were collected by centrifugation at $14,000 \times g$ for $20 \mathrm{sec}$, washed one time with $0.5 \mathrm{ml}$ of ice-cold lysis buffer, solubilized in $60 \mu \mathrm{l}$ of SDS-PAGE sample buffer, electrophoresed on an 11.5\% SDS-PAGE gel, and transferred to an Immobilon membrane. The membrane was exposed to a Storm PhosphorImager screen (Molecular Dynamics) to detect radioactive proteins before being subjected to immunoblot analysis with antimCAR (LUMIJ), S, or M opsin antibodies.

\section{Results}

Membrane association of mCAR in a light-dependent and GRK1-dependent manner

To explore whether CAR contributes to quenching lightactivated cone opsins in the mammalian retina, we analyzed the redistribution of $\mathrm{mCAR}$ to retinal membranes in response to light. The distribution of mCAR and mouse SAG (mSAG) was analyzed by immunoblot analysis of membrane and soluble proteins of retinal homogenates from either light- or dark-adapted mice. Figure 1 shows that $50 \%$ of the mCAR protein is in the membrane fraction (pellet) in the dark-adapted retina, whereas $81 \%$ is in the membrane fraction in the light-adapted retina (Fig. $1 A)$, similar to the distribution of mSAG, which is mostly in the soluble fraction in the dark-adapted retina but redistributes to the membranes when exposed to light (Fig. 1C). These results are consistent with our previous observation that a portion of the mCAR immunoreactivity translocates to the cone outer segments in a light-dependent manner (Zhu et al., 2002b). Interestingly, in the Grk $1^{-/-}$mouse retina (Fig. $1 B, D$ ) neither mCAR nor mSAG has a significant increase in membrane binding after light exposure as compared with the dark-adapted retinas, implying that
A

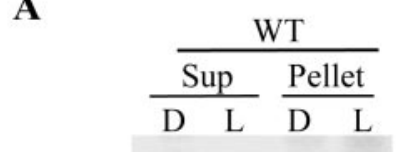

B
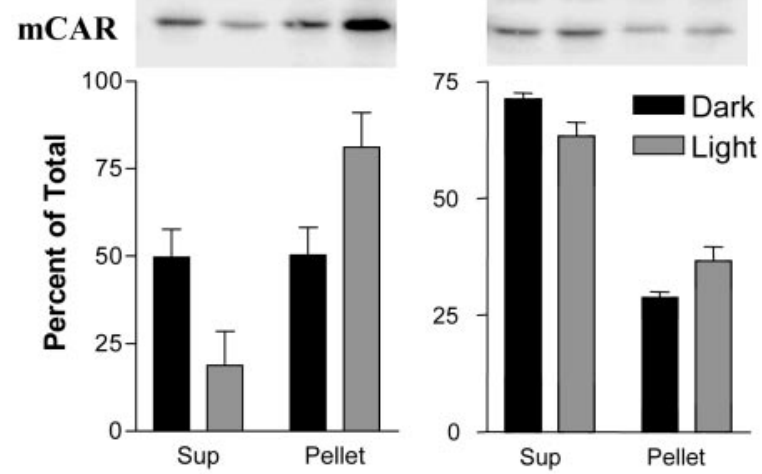

C

D

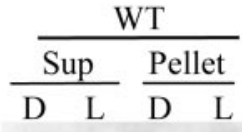

mSAG

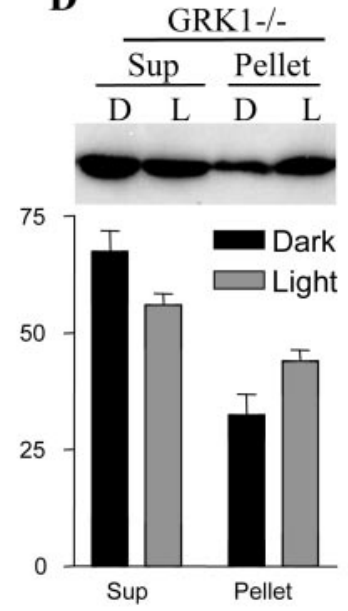

Figure 1. Light- and GRK1-dependent membrane association of mCAR. Adult WT or Grk1 ${ }^{-1-}$ mice were killed either at mid-day in the light or dark-adapted overnight and killed in the dark under IR light. The retinas were dissected under room light from light-adapted mice (L) or under IR light from dark-adapted mice (D) and were homogenized. The supernatants (Sup; soluble fraction) and pellets (membrane fraction) were separated by centrifugation, and the pellets were resuspended in the same volume of buffer. Equal volumes of proteins were resolved on replicate $11.5 \%$ SDS-PAGE gels and transferred to PVDF membranes, which were detected with the mCAR (LUMIJ) or rod arrestin ( $\mathrm{MSAG}, \mathrm{C10C10}$ ) antibodies with an ECL kit. In each panel a representative immunoblot and a histogram representing quantitative data (mean \pm SEM) from at least three immunoblots are shown.

the membrane binding of mCAR may be phosphorylationdependent and that GRK1 may play a role in both rod and cone phototransduction in the mouse retina.

\section{Generation and characterization of anti-mouse $S$ and $M$ opsin antibodies}

To facilitate our cone opsin phosphorylation studies, we generated rabbit polyclonal antibodies against peptides derived from mouse $S$ and $M$ opsin peptide sequences and affinity-purified them against their respective peptide. Immunoblot analysis of retinal homogenates from normal $\mathrm{C} 57 \mathrm{BL} / 6 \mathrm{~J}$ mice with the two affinity-purified antibodies identified a single band of the predicted molecular weight of the respective opsin, i.e., $37.5 \mathrm{kDa}$ for $\mathrm{S}$ opsin and $39 \mathrm{kDa}$ for $\mathrm{M}$ opsin (Fig. 2A,B). Minor bands were seen after a longer film exposure time (data not shown). To verify the specificity of the antibodies, we did a peptide-blocking experiment by incubating the primary antibody with 100 times excess 


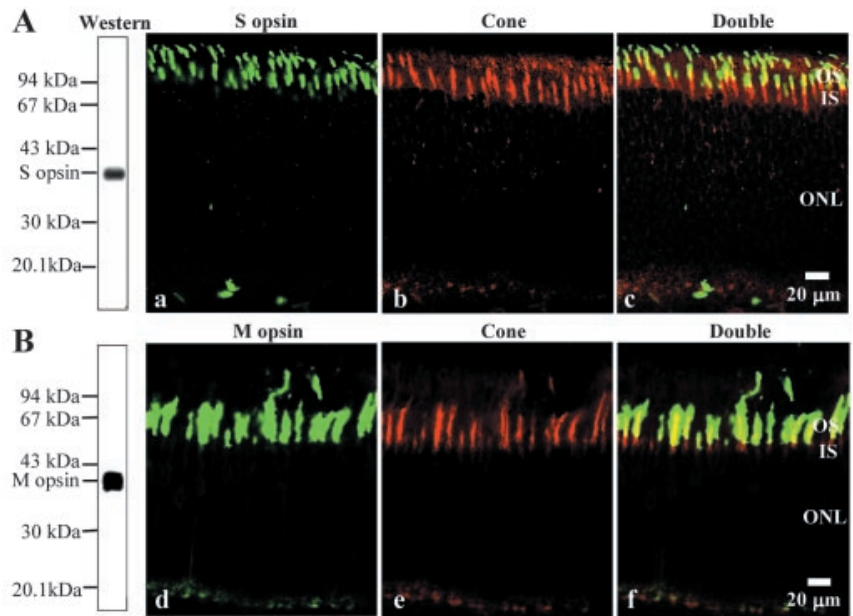

Figure 2. Characterization of anti-mouse S opsin $(A)$ and $M$ opsin $(B)$ antibodies by Western blotting and immunohistochemistry. Western blot analysis was performed with normal adult C57BL/6J mouse whole retinal homogenate, and immunohistochemistry was done on $\mathrm{C57BL} / 6 \mathrm{~J}$ mouse retinal frozen sections. Cone photoreceptor cells were labeled with biotinylated peanut agglutinin and visualized with Texas Red-avidin D in red $(b, e)$. S and M opsins were labeled with anti-S and anti-M opsin polyclonal antibodies, respectively, and visualized with fluorescein label in green $(a, d)$. Dual immunofluorescence labeling verified both $S$ and $M$ opsin immunoreactivities localized to cone cells $(c, f)$. OS, Outer segments; IS, inner segments; ONL, outer nuclear layer. Scale bar, $20 \mu \mathrm{m}$.

(mol peptide/mol specific antibody) of the specific peptide used to generate the antibody and found that only the major band was blocked completely by the peptide (data not shown). When the primary antibody was omitted and only the secondary antibody was incubated with the blot, all of the minor bands were observed, but the major one was missing (data not shown), suggesting that the minor bands were caused by cross-reaction with the secondary antibody.

Immunohistochemistry that used mouse retinal sections revealed specificity of both antibodies for cone photoreceptor outer segments (Fig. 2A,B). The cone outer segment staining was blocked completely by the specific peptide used to generate the antibody (data not shown).

\section{Both GRK1 and mCAR are expressed in both $S$ and $M$ cone photoreceptors}

Previous studies have shown the expression of both GRK1 (Lyubarsky et al., 2000) and mCAR (Zhu et al., 2002b) in cone photoreceptors of normal mouse retinas. Both GRK1 and mCAR also are expressed in the retina of the $\mathrm{Nrl}^{-/-}$mouse by Western and Northern blot analyses, respectively (Mears et al., 2001). We examined the colocalization of either GRK1 or mCAR with S and M opsins by immunohistochemistry. In the normal C57BL/6J mouse retina GRK1 is expressed in both $S$ and $M$ cones, in addition to rods, and is localized exclusively to the outer segments (Fig. 3) in contrast to mCAR, which has a diffuse staining pattern throughout the whole cell body of the cone photoreceptors (Fig. 3J,K) (Zhu et al., 2002b). Immunofluorescent double labeling of whole-mounted mouse retinas shows that mCAR also is localized in both S and M cones (Fig. 4), consistent with the distribution of human CAR in all cone photoreceptors (Sakuma et al., 1996; Zhang et al., 2001).

In the $\mathrm{Nrl}^{-1-}$ mouse retina (Fig. 5) GRK1 is colocalized with either S or M opsin to the short outer segments of all photoreceptors, whereas mCAR is expressed throughout the whole photoreceptor layer, with the most intense staining in the outer segments
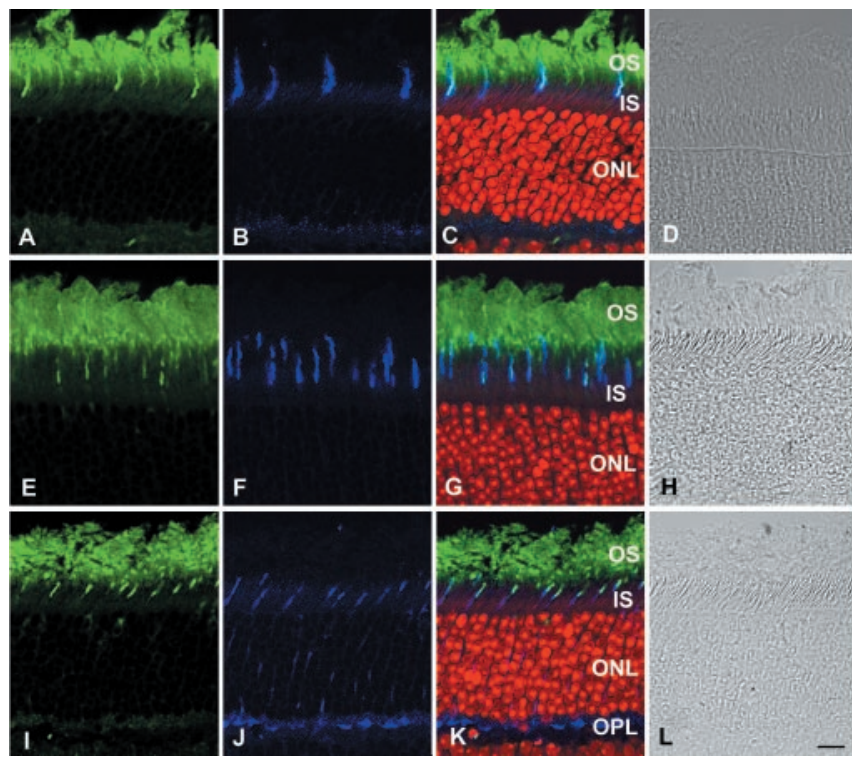

Figure 3. Localization of GRK1 in both $\mathrm{S}$ and $\mathrm{M}$ cone photoreceptors of the normal mouse retina. Adult C57 mouse retinal frozen sections were triple labeled fluorescently with the GRK1specific monoclonal antibody $\mathrm{D} 11(A, E, I)$, the fluorescent nuclear dye $\mathrm{PI}$ (red in $C, G, K)$, and the polyclonal anti-S opsin $(B)$, anti-M opsin ( $F$ ), or anti-mCAR (LUMIJ, J). Overlay of $A$ and $B$ with PI staining $(C)$ or $E$ and $F$ with PI staining $(G)$ reveals colocalization of GRK1 with both $S$ opsins $(C)$ and $M$ opsins $(G)$ in the cone outer segments, and overlay of $/$ and $J$ with PI staining $(K)$ shows colocalization of GRK1 with mCAR also in the cone outer segments. A phase-contrast image $(D, H, L)$ also is shown for each section. Note that the staining of GRK1 and $S$ and $M$ opsins is restricted to the outer segments (OS), whereas the staining of mCAR is diffused throughout the cone photoreceptors but condensed in the cone outer segments and the synaptic terminals. IS, Inner segments; ONL, outer nuclear layer; OPL, outer plexiform layer. Scale bar, $20 \mu \mathrm{m}$.
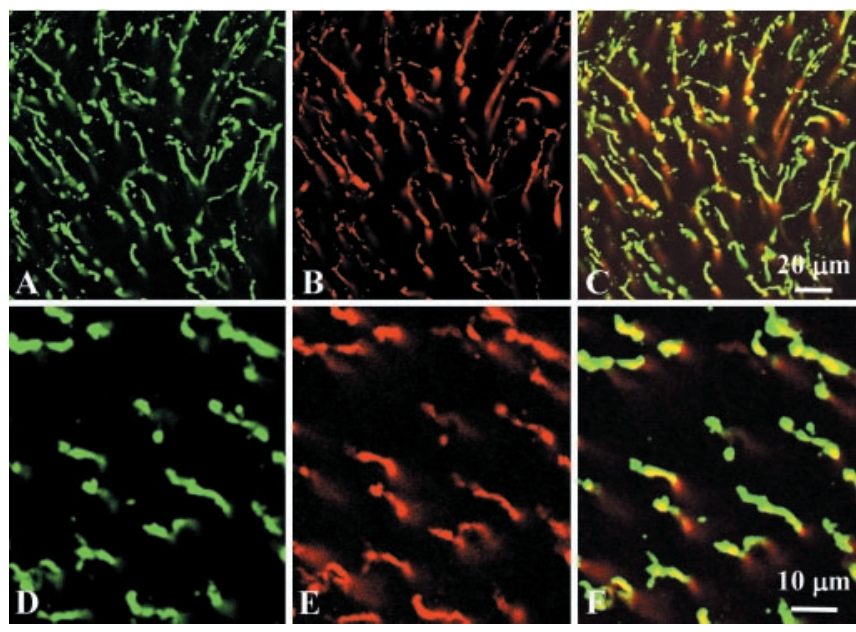

Figure 4. Localization of $\mathrm{mCAR}$ in both $\mathrm{S}$ and $\mathrm{M}$ cone photoreceptors of the normal mouse retina. Adult $\mathrm{C} 57$ mouse retinal whole mounts were double labeled immunofluorescently with either anti-S $(A)$ or anti-M opsin antibody $(D)$ and the anti-mCAR antibody LUMIJ $(B, E)$. Overlay of $A$ and $B(C)$ or $D$ and $E(F)$ reveals colocalization of $m C A R$ with both $S$ and $M$ opsins in the cone outer segments.

and the synaptic terminals. mCAR also is colocalized with both S and $\mathrm{M}$ opsins in the outer segments of the $\mathrm{Nrl}^{-/-}$retinas.

Light- and GRK1-dependent phosphorylation of cone opsins

To determine cone opsin phosphorylation after light exposure, we examined the light-dependent incorporation of ${ }^{32} \mathrm{P}$ orthophosphate into the pure-cone retinas of the $\mathrm{Nrl}^{-/-}$mice. Exposure of isolated intact retinas from $\mathrm{Nrl}^{-1-}$ mice to bright 

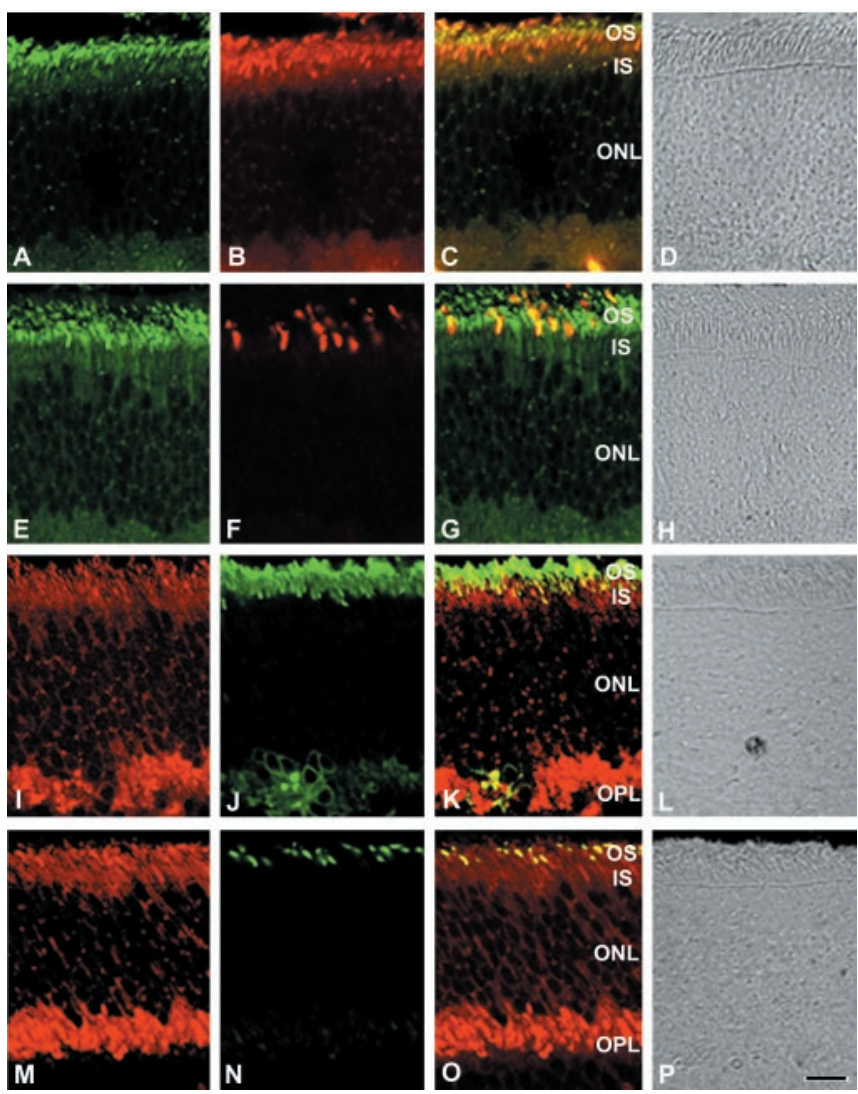

Figure 5. GRK1 and mCAR both are expressed in all photoreceptors of the $\mathrm{Nrl}^{-1-}$ mouse retina. Adult $\mathrm{Nrl}^{-1-}$ mouse retinal frozen sections were double labeled fluorescently with D11 $(A)+\operatorname{anti}-S$ opsin $(B)$, D11 (E) + anti-M opsin (F), LUMIJ (I) + anti-S opsin (J), and LUMIJ (M) + anti-M opsin $(N)$. Overlay of $A$ and $B(C)$ or $E$ and $F(G)$ reveals colocalization of GRK 1 with both Sopsins ( $($ and $M$ opsins $(G)$ in the short outer segments, and overlay of $/$ and $J(K)$ or $M$ and $N(O)$ shows colocalization of $\mathrm{mCAR}$ with both $\mathrm{S}$ and $\mathrm{M}$ opsins also in the outer segments. Note that the staining of GRK1 and $S$ and $M$ opsins is restricted to the outer segment layer (OS), whereas the staining of $m C A R$ is diffused throughout the photoreceptors but condensed in the outer segments and the synaptic terminals. A phase-contrast image $(D, H, L, P)$ is shown for each section. IS, Inner segments; ONL, outer nuclear layer; OPL, outer plexiform layer. Scale bar, 20 $\mu \mathrm{m}$.

sunlight $(\sim 8000 \mathrm{fc})$ resulted in phosphorylation of both $\mathrm{S}$ and $\mathrm{M}$ opsins, which was not observed in retinas from WT mice, presumably because of masking by the abundant phosphorylated rhodopsin (Fig. 6A). Retinas that were kept in darkness did not show appreciable levels of opsin phosphorylation in either of the two mouse lines (Fig. 6A). We chose sunlight as the stimulus because it is a naturally occurring light source, and it contains a strong UV component, which can activate the murine $S$ opsin most efficiently (peak sensitivity at $\sim 360 \mathrm{~nm}$ ). However, 10 min of room light exposure also resulted in the phosphorylation of both $\mathrm{S}$ and $\mathrm{M}$ opsins (data not shown).

To investigate the role of GRK1 in cone opsin phosphorylation, as indicated by the analysis of the $\mathrm{Grk} 1^{-1-}$ mice (Lyubarsky et al., 2000), we bred $\mathrm{Nrl}^{-\prime-}$ mice with Grk1 ${ }^{-\prime-}$ mice, and we analyzed the double knock-out mice lacking both $\mathrm{Nrl}$ and Grk1 $\left(\mathrm{Nrl}^{-I-} \mathrm{Grk1}^{-1-}\right)$. Neither S nor M opsin was phosphorylated in the $\mathrm{Nrl}^{-1-} \mathrm{Grkl}^{-1-}$ mouse retina after light exposure (Fig. 6A), although the double $\mathrm{KO}$ retinas had the same morphology as those of the $\mathrm{Nrl}^{-1-}$ mice (data not shown), and both $\mathrm{S}$ and $\mathrm{M}$ opsins were expressed in the double $\mathrm{KO}$ mouse retina at equivalent levels to those in the $\mathrm{Nrl}^{-1-}$ mouse retina (Fig. $6 B$ ).
A
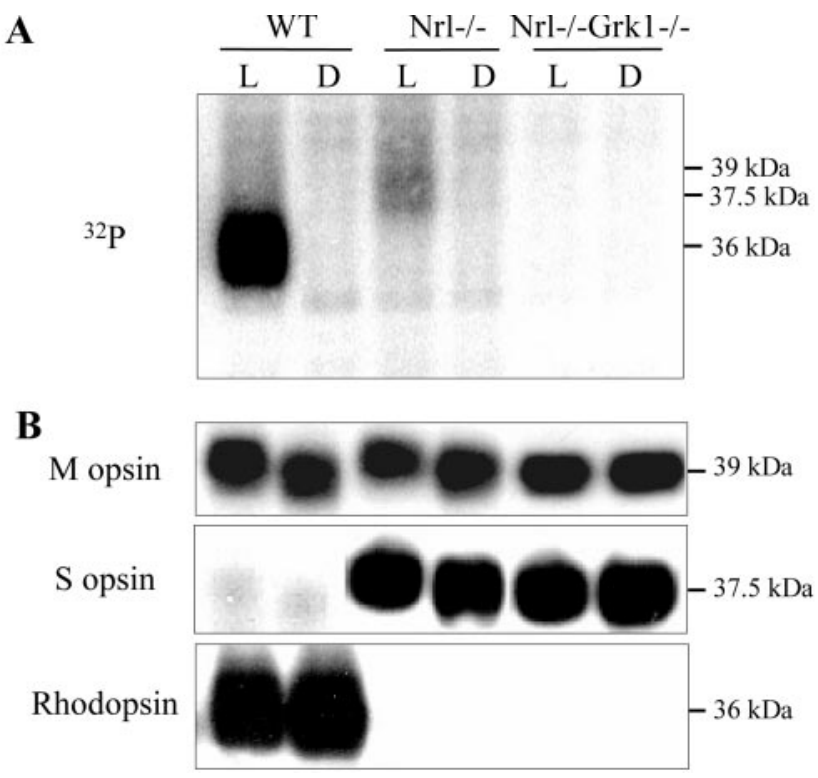

Figure 6. In situ light-dependent phosphorylation of opsins ex vivo. $A$, In situ phosphorylation of opsins. WT, $\mathrm{Nrl}^{-1-}$, and $\mathrm{Nrl}^{-1-} \mathrm{Grk} 1^{-1-}$ mice were dark-adapted overnight and killed. The retinas were dissected under IR light and incubated in phosphate-free Krebs' buffer containing $1.25 \mathrm{mCi} / \mathrm{ml}^{32} \mathrm{P}$ orthophosphate for $30 \mathrm{~min}$ at RT in the dark. One retina of each strain was homogenized in SDS sample buffer in the dark (D) while the other retina was exposed to bright sunlight $(\mathrm{L})$ for $10 \mathrm{~min}$ before homogenization. The proteins were resolved on an $11.5 \%$ SDS-PAGE gel and transferred to a PVDF membrane. Opsin phosphorylation was detected by autoradiography on a Phosphorlmager screen. $B$, Immunoblot analysis of the same membrane in $A$, using polyclonal antibodies to mouse $S$ or $M$ opsin or the rhodopsin monoclonal antibody $1 \mathrm{D} 4$, sequentially, to observe the quantity and location of the opsins relative to the radioactive phosphate $\left.{ }^{32} \mathrm{P}\right)$ identified in $A$. Note the slightly higher molecular weight of the phosphorylated as compared with the unphosphorylated species of $S$ and $M$ opsin and rhodopsin.

\section{Phosphorylation of cone opsins at multiple sites}

Recent evidence shows that multiple phosphorylation of rhodopsin at the $\mathrm{C}$ terminus is necessary for rapid and reproducible deactivation of rhodopsin (Mendez et al., 2000), which is consistent with earlier observations that up to nine phosphates could be incorporated into a single $\mathrm{R}^{\star}$ in vitro (Wilden and Kuhn, 1982) and that the addition of each phosphate reduces the ability of $\mathrm{R}^{\star}$ to activate transducin (Arshavsky et al., 1987; Wilden, 1995). Mass spectrometric analysis further confirmed multiple phosphorylation of rhodopsin in vivo (Kennedy et al., 2001). As many as 9 and 12 potential phosphorylation sites exist in the $S$ and $M$ opsin C-terminal sequences, respectively (Fig. 7A). To explore the possibility of multiple phosphorylation of cone opsins, we performed IEF with retinas from $\mathrm{Nrl}^{-1-}$ mice. Immunoblot analysis of IEF gels of solubilized membrane fractions from $\mathrm{Nrl}^{-1-}$ mouse retinas exposed to direct bright sunlight reveals potentially nine phosphorylated species of $S$ opsin (Fig. 7B), implying that all serine and threonine residues near the $\mathrm{C}$ terminus of S opsin can be phosphorylated with exposure to naturally occurring bright light. Because of the much lower expression level of $\mathrm{M}$ opsin in these mouse retinas as compared with S opsin, we detected only five phosphorylated species of M opsin. However, other species with more than five phosphates may exist but may be beyond our sensitivity of detection. Under the same experimental conditions we detected only five phosphorylated species of rhodopsin in WT mouse retina, although up to six have been reported (Mendez et al., 2000). In the samples kept in darkness a monophosphorylated species of each opsin was detected in addition to the predominant unphosphorylated species (Fig. 7B). Pre- 


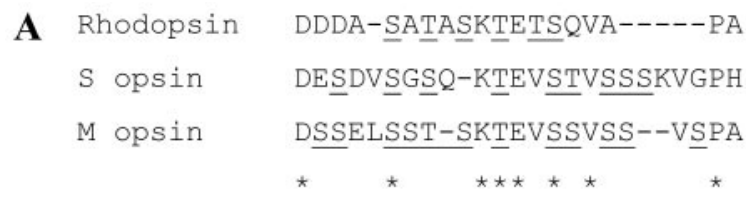

B

$\mathrm{Nrl}-/-$
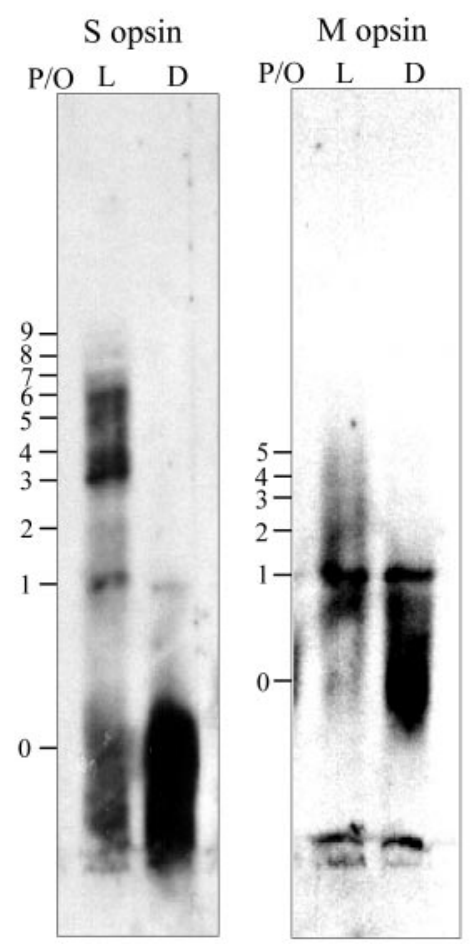

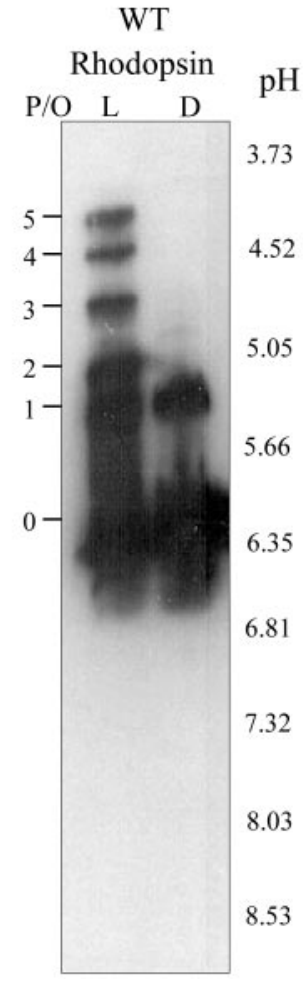

Figure 7. Multiple phosphorylation of $S$ and $M$ opsins ex vivo. A, Alignment of C-terminal sequences for mouse rhodopsin and $S$ and $M$ opsins. The conserved amino acids among all three opsins are indicated with an asterisk. Potential phosphorylation sites (serine and threonine residues) are underlined. B, Separation of $S$ and $M$ opsin and rhodopsin and their phosphorylated species by isoelectric focusing (IEF). Retinas from $\mathrm{Nrl}^{-1-}$ ( $\mathrm{S}$ and M opsins) and WT mice (rhodopsin) were dissected under infrared light, exposed to direct bright sunlight ( $\sim 8000 \mathrm{fc}$ ) for $10 \mathrm{~min}$ (L), or kept in total darkness (D). Samples were processed as described in Materials and Methods, and a fraction corresponding to one-tenth of a retina was applied per lane. The $\mathrm{pH}$ gradient of the gel is indicated on the right. Phosphorylated $S$ and $M$ opsin and rhodopsin species with an increasing number of phosphates per opsin $(\mathrm{P} / 0)$ yielded bands at increasingly acidic $\mathrm{pH}$.

vious studies have shown that $2 \%$ of rhodopsin is monophosphorylated in the dark-adapted mouse retina either in the presence or absence of GRK1 (Chen et al., 1999). The significance of opsin monophosphorylation in the dark currently is unknown. Alternatively, the second band above the unphosphorylated species that is present in both dark and light conditions may be caused by other post-translational modifications of the cone pigments.

\section{Coimmunoprecipitation of mCAR with light-activated, phosphorylated cone opsins}

To examine whether mCAR interacts with light-activated, phosphorylated cone opsins, we performed IP on $\mathrm{Nrl}^{-/-}$mouse retinal proteins with either the mCAR antibody or cone opsin antibodies as well as the CRX antibody, which is also an affinitypurified rabbit polyclonal antibody (Zhu and Craft, 2000), as a negative control. Both the anti-mCAR antibody LUMIJ $(\alpha-$ $\mathrm{mCAR}$ ) and the anti-cone opsin antibodies ( $\alpha$-S and $\alpha$-M opsin) coimmunoprecipitated phosphorylated proteins $\left({ }^{32} \mathrm{P}\right)$ only in
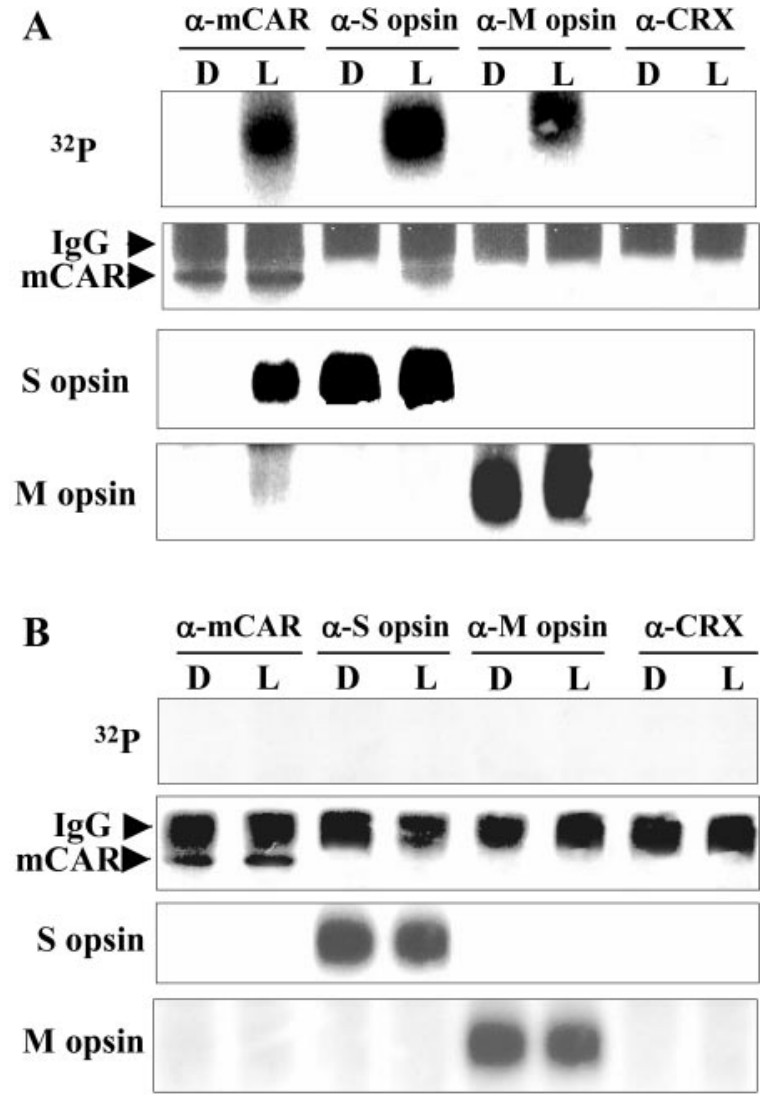

Figure 8. Coimmunoprecipitation of mCAR with light-activated, phosphorylated cone opsins. $A$, Coimmunoprecipitation of mCAR with phosphorylated $S$ and $M$ opsins from lightexposed $\mathrm{Nrl}^{-1-}$ mouse retinas. $\mathrm{Nrl}^{-1-}$ mouse retinas were dissected under IR light from dark-adapted mice and incubated in phosphate-free Krebs' buffer containing $1.25 \mathrm{mCi} / \mathrm{ml}^{32} \mathrm{P}$ orthophosphate for $30 \mathrm{~min}$. Four retinas were exposed to bright sunlight ( $\sim 8000 \mathrm{fc})$ for $10 \mathrm{~min}$ while another four retinas remained in the dark. The retinas were homogenized in lysis buffer, and the supernatant was immunoprecipitated with rabbit polyclonal antibodies against $\mathrm{m} C \mathrm{AR}$ ( $\alpha$-mCAR), Sopsin ( $\alpha$-Sopsin), M opsin ( $\alpha$-M opsin), or CRX ( $\alpha$-CRX). The precipitated proteins were resolved on SDS-PAGE gels and transferred to PVDF membranes. Phosphorylated opsins $\left({ }^{32} \mathrm{P}\right)$ were detected by exposing the membranes to a Phosphorlmager screen. Then the membranes were subjected to Western blot analysis with antibodies against $\mathrm{mCAR}$ and $\mathrm{S}$ and $\mathrm{M}$ opsins. B, Immunoprecipitation with the same antibodies as in $A$ from the $\mathrm{Nrl}^{-1-} \mathrm{Grk} 1^{-1-}$ mouse retinas. Note the lack of phosphorylation of either $S$ or $M$ opsin even after light exposure. Also, mCAR is not coimmunoprecipitated with either of the cone opsins.

the light-exposed retina, whereas the anti-CRX antibody ( $\alpha$ CRX) did not coimmunoprecipitate any phosphorylated proteins either in the light-exposed or dark-adapted retinas. The mCAR antibody precipitated an equal amount of mCAR protein from both the light-exposed and the dark-adapted retinas. However, only in the light-exposed retinas, when cone opsins were activated and phosphorylated, did the mCAR antibody coprecipitate $S$ and $M$ opsins. Also, both the $S$ and $M$ opsin antibodies precipitated an equal amount of their respective opsin proteins from both the light-exposed and dark-adapted retinas, but the $\mathrm{S}$ opsin antibody coprecipitated mCAR only from the lightexposed retinal homogenate. The $\mathrm{M}$ opsin antibody, however, did not precipitate appreciable levels of mCAR protein either from the light-exposed or dark-adapted retinas (Fig. 8A), most likely because of the sensitivity limit of the assay.

In the $\mathrm{Nrl}^{-1-} \mathrm{Grk1}^{-1-}$ mouse retina (Fig. $8 \mathrm{~B}$ ), where no cone opsin phosphorylation occurred after light activation (Fig. 6A), no ${ }^{32} \mathrm{P}$-labeled proteins were precipitated by any of the antibodies. The mCAR antibody did not pull down either cone opsin, nor 
did the cone opsin antibodies pull down mCAR either in the light-exposed or dark-adapted retina, although each antibody pulled down equal amounts of its corresponding protein from both the light-exposed and dark-adapted retinas (Fig. $8 \mathrm{~B}$ ). These results further confirm that the phosphorylated protein bands in the ${ }^{32} \mathrm{P}$ incorporation experiments (Fig. $6 \mathrm{~A}$ ) and in the coimmunoprecipitation experiments with the $\mathrm{Nrl}^{-1-}$ mice (Fig. $8 A$ ) are GRK1-phosphorylated cone opsins and that the binding of mCAR to cone opsins is phosphorylation-dependent, similar to rod arrestin binding to phosphorylated $\mathrm{R}^{\star}$.

\section{Discussion}

In the vertebrate retina two distinct cell populations of photoreceptors, rods and cones, coexist. Rods are specialized for dim light vision, whereas cones provide high-acuity color vision. Although cones comprise only $5 \%$ of photoreceptors in the human retina, they are far more important than rods for vision in daylight. Even at night our world is flooded with enough artificial light so that our cones can function, and we can see clearly in color. Despite its importance in vision the cone phototransduction cascade and its underlying molecular mechanisms are poorly understood. In this study we aimed to explore the potential involvement of opsin phosphorylation and CAR binding in the cone phototransduction cascade, using mouse models lacking rods and/or GRK1.

\section{Cone opsin phosphorylation in the mammalian retina}

Two critical events, receptor phosphorylation and arrestin binding, participate in the deactivation of GPCRs (Freedman and Lefkowitz, 1996; Krupnick et al., 1997; Krupnick and Benovic, 1998; Pitcher et al., 1998). In rod photoreceptors the phosphorylation of $\mathrm{R}^{\star}$ by GRK1 initiates deactivation and limits the response amplitude (J. Chen et al., 1995; C. Chen et al., 1999). In the absence of arrestin, phosphorylation alone can decrease the catalytic activity of $\mathrm{R}^{\star}$ by $50 \%$ (Xu et al., 1997).

Cone opsins from the all-cone retina of lizard, from the conedominant retina of chicken, and from the rod-dominant retina of carp are phosphorylated in vitro either by the endogenous kinase or by bovine GRK1 (Walter et al., 1986; Fukada et al., 1990; Tachibanaki et al., 2001). In the present study, using the purecone retinas of the $\mathrm{Nrl}^{-1-}$ mice, we have provided the first biochemical evidence of cone opsin phosphorylation in a mammalian species. It is puzzling why, in the rhodopsin $\mathrm{KO}$ mouse retina, no light-dependent phosphorylation signals are observed, although these mice contain fully functional cones at $4-5$ weeks of age (Mendez et al., 2000). Because cones account for only 3\% of the photoreceptors in the mouse retina (Carter-Dawson and LaVail, 1979; Jeon et al., 1998), the light-dependent cone opsin phosphorylation signals may have been masked by the nonlightdependent phosphorylation signals from other phosphoproteins.

\section{GRK1 is responsible for light-dependent cone opsin phosphorylation in the mouse retina}

Seven distinct mammalian GRKs, each differing in tissue distribution and in regulatory properties, have been identified to date. Among these enzymes GRK1 is involved in phototransduction. Proof that GRK1 phosphorylation of $\mathrm{R}^{\star}$ is required for normal inactivation of $\mathrm{R}^{*}$ in vivo has come from single-cell recordings of photoresponses in rods expressing mutant rhodopsin lacking the C terminus (Chen et al., 1995) and, more recently, of responses of rods in Grk1 ${ }^{-1-}$ mice (Chen et al., 1999).

GRK1 is localized in both rod and cone photoreceptors in many species, including the rod-dominant human, monkey, and mouse (Zhao et al., 1998; Lyubarsky et al., 2000; Weiss et al., 2001) and the cone-dominant chicken (Zhao et al., 1999). Although a cone-specific GRK7 has been reported recently in retinas of both cone- and rod-dominant species, the absence of GRK7 protein in the mouse photoreceptor outer segment layer rules out the possibility that GRK7 is responsible for cone opsin phosphorylation in the mouse retina (Chen et al., 2001). Functional analysis of mouse retinas lacking GRK1 expression shows defects in the recovery of cone-driven photoresponses (Lyubarsky et al., 2000). Consistent with this observation, we found that mCAR lost its light-dependent binding to the membrane fraction in the Grk1 $1^{-1-}$ mouse retina, similar to the behavior of rod arrestin (Fig. $1 B, D$ ). The colocalization of GRK1 with both S and $\mathrm{M}$ opsins and the lack of light-dependent phosphorylation signals in the $\mathrm{Nrl}^{-/-} \mathrm{Grk1}^{-/-}$double KO mouse retina suggest that GRK1 is the responsible kinase for cone opsin phosphorylation during phototransduction in the mouse retina. Electrophysiological analysis of the photoresponses of the photoreceptors of the $\mathrm{Nrl}^{-1-} \mathrm{Grk}^{-1-}$ mouse retina will verify the functional significance of cone opsin phosphorylation.

In contrast to the Grk1 ${ }^{-/-}$mouse phenotype, human patients with Grk1 null mutation have either normal or slightly abnormal photopic vision (Cideciyan et al., 1998). A detailed study of species-specific differences in GRK1 and GRK7 expression reveals that the cones of mice and rats express only GRK1, and the cones of pigs and dogs express only GRK7, whereas primate cones coexpress both GRK7 and GRK1 (Weiss et al., 2001). The expression of GRK7 in human cones may compensate partly for the loss of GRK1 in patients with Grk1 null mutation. Recent studies reveal that the deactivation kinetics of $S$ cones in human patients with enhanced S-cone syndrome (ESCS) were much slower than long/middle wavelength-sensitive (L/M) cones in normal, ESCS, or GRK1-null Oguchi retinas (Cideciyan et al., 2003). Immunocytochemistry reveals no expression of either GRK1 or GRK7 in ESCS S cones, whereas ESCS L/M cones have no GRK7 and have only GRK1. These results suggest that the absence of both GRK1 and GRK7 causes a greater degree of abnormality in cone deactivation than that caused by the deficiency of either GRK alone (Cideciyan et al., 2003). Although the relative roles of GRK7 and GRK1 in primate cones still await elucidation, the above data clearly demonstrate that opsin phosphorylation is a critical component of the deactivation mechanisms in cone photoreceptors of the human retina.

The role of GRK1 in rods is to inactivate $\mathrm{R}^{\star}$ that, in concert with regeneration, leads to the recovery of sensitivity (Cideciyan et al., 1998). Because cones recover sensitivity much faster than rods and the maximal rate of visual pigment regeneration is 2000fold higher in cones than in rods (Schnapf et al., 1990), it is expected that the rate of cone opsin phosphorylation is also much faster than that of rhodopsin. Indeed, Tachibanaki and coworkers have reported that phosphorylation is $>20$ times faster in cone cell membranes than in rod membranes in the carp retina after light activation (Tachibanaki et al., 2001). Recently, an alternate visual cycle that regenerates visual pigments at a rate 20fold faster than the known visual cycle has been demonstrated, which is proposed to be responsible for sustained daylight vision mediated by cone photoreceptors (Mata et al., 2002). Studies of the kinetics of phosphorylation of mammalian rod and cone opsins after light activation are underway, using retinal membrane preparations from WT (rhodopsin) and $\mathrm{Nrl}^{-1-}$ mice (S opsin). 


\section{CAR is involved in the cone phototransduction cascade}

Members of the arrestin family are involved in GPCR desensitization, internalization, and GPCR-mediated activation of MAPK pathways. In the rod photoreceptor the rod arrestin binding after receptor phosphorylation is necessary to complete the quench of the light-activated phototransduction cascade (Wilden et al., 1986b; Xu et al., 1997). CAR has been identified in many vertebrates (Craft et al., 1994; Abdulaeva et al., 1995; Craft and Whitmore, 1995; Hisatomi et al., 1997; Maeda et al., 2000; Smith et al., 2000; Zhu et al., 2002a,b). Its high sequence homology to other arrestins and its cone photoreceptor localization suggest that CAR may play a key role in the modulation of phototransduction in cones as rod arrestin does in rods. Our previous studies showed that mCAR binds to purified embryonic chicken outer segment membranes in a light- and phosphorylation-dependent manner and that a portion of the mCAR protein translocates to the cone outer segments in the mouse retina after light exposure (Zhu et al., 2002b). The results presented here provide further evidence that CAR behaves like rod arrestin in response to light, suggesting that CAR may be involved in the shutoff mechanisms of the cone phototransduction cascade by binding to light-activated, phosphorylated cone opsins.

To elucidate further the function of CAR, we are creating mCAR KO mice. Characterization of the morphological, biochemical, and electrophysiological phenotypes of these mice will clarify the physiological role of CAR in the shutoff of cone phototransduction as well as verify its other functions in both the retina and the pineal gland.

\section{References}

Abdulaeva G, Hargrave PA, Smith WC (1995) The sequence of arrestins from rod and cone photoreceptors in the frogs Rana catesbeiana and Rana pipiens. Localization of gene transcripts by reverse-transcription polymerase chain reaction on isolated photoreceptors. Eur J Biochem 234:437-442.

Arshavsky V, Antoch MP, Philippov PP (1987) On the role of transducin GTPase in the quenching of a phosphodiesterase cascade of vision. FEBS Lett 224:19-22.

Baylor D (1996) How photons start vision. Proc Natl Acad Sci USA 93:560-565.

Baylor DA, Burns ME (1998) Control of rhodopsin activity in vision. Eye 12:521-525.

Baylor DA, Lamb TD, Yau KW (1979) The membrane current of single rod outer segments. J Physiol (Lond) 288:589-611.

Bessant DA, Payne AM, Mitton KP, Wang QL, Swain PK, Plant C, Bird AC, Zack DJ, Swaroop A, Bhattacharya SS (1999) A mutation in NRL is associated with autosomal dominant retinitis pigmentosa. Nat Genet 21:355-356

Carter-Dawson LD, LaVail MM (1979) Rods and cones in the mouse retina. I. Structural analysis using light and electron microscopy. J Comp Neurol 188:245-262.

Chen CK, Burns ME, Spencer M, Niemi GA, Chen J, Hurley JB, Baylor DA, Simon MI (1999) Abnormal photoresponses and light-induced apoptosis in rods lacking rhodopsin kinase. Proc Natl Acad Sci USA 96:3718-3722.

Chen CK, Zhang K, Church-Kopish J, Huang W, Zhang H, Chen YJ, Frederick JM, Baehr W (2001) Characterization of human GRK7 as a potential cone opsin kinase. Mol Vis 7:305-313.

Chen J, Makino CL, Peachey NS, Baylor DA, Simon MI (1995) Mechanisms of rhodopsin inactivation in vivo as revealed by a COOH-terminal truncation mutant. Science 267:374-377.

Cideciyan AV, Zhao X, Nielsen L, Khani SC, Jacobson SG, Palczewski K (1998) Null mutation in the rhodopsin kinase gene slows recovery kinetics of rod and cone phototransduction in man. Proc Natl Acad Sci USA 95:328-333.

Cideciyan AV, Jacobson SG, Gupta N, Osawa S, Locke KG, Weiss ER, Wright AF, Birch DG, Milam AH (2003) Cone deactivation kinetics and GRK1/
GRK7 expression in enhanced S cone syndrome caused by mutations in NR2E3. Invest Ophthalmol Vis Sci 44:1268-1274.

Craft CM, Whitmore DH (1995) The arrestin superfamily: cone arrestins are a fourth family. FEBS Lett 362:247-255.

Craft CM, Whitmore DH, Wiechmann AF (1994) Cone arrestin identified by targeting expression of a functional family. J Biol Chem [Erratum (1994) 269:17756] 269:4613-4619.

Craft CM, Xu J, Slepak VZ, Zhan-Poe X, Zhu X, Brown B, Lolley RN (1998) PhLPs and PhLOPs in the phosducin family of $G \beta \gamma$ binding proteins. Biochemistry 37:15758-15772.

Fain GL, Matthews HR, Cornwall MC, Koutalos Y (2001) Adaptation in vertebrate photoreceptors. Physiol Rev 81:117-151.

Freedman NJ, Lefkowitz RJ (1996) Desensitization of G-protein-coupled receptors. Recent Prog Horm Res 51:319-351.

Fukada Y, Kokame K, Okano T, Shichida Y, Yoshizawa T, McDowell JH, Hargrave PA, Palczewski K (1990) Phosphorylation of iodopsin, chicken red-sensitive cone visual pigment. Biochemistry 29:10102-10106.

Hisatomi O, Imanishi Y, Satoh T, Tokunaga F (1997) Arrestins expressed in killifish photoreceptor cells. FEBS Lett 411:12-18.

Hisatomi O, Matsuda S, Satoh T, Kotaka S, Imanishi Y, Tokunaga F (1998) A novel subtype of G-protein-coupled receptor kinase, GRK7, in teleost cone photoreceptors. FEBS Lett 424:159-164.

Jeon CJ, Strettoi E, Masland RH (1998) The major cell populations of the mouse retina. J Neurosci 18:8936-8946.

Kennedy MJ, Lee KA, Niemi GA, Craven KB, Garwin GG, Saari JC, Hurley JB (2001) Multiple phosphorylation of rhodopsin and the in vivo chemistry underlying rod photoreceptor dark adaptation. Neuron 31:87-101.

Krupnick JG, Benovic JL (1998) The role of receptor kinases and arrestins in G-protein-coupled receptor regulation. Annu Rev Pharmacol Toxicol 38:289-319.

Krupnick JG, Gurevich VV, Benovic JL (1997) Mechanism of quenching of phototransduction. Binding competition between arrestin and transducin for phosphorhodopsin. J Biol Chem 272:18125-18131.

Leskov IB, Klenchin VA, Handy JW, Whitlock GG, Govardovskii VI, Bownds MD, Lamb TD, Pugh Jr EN, Arshavsky VY (2000) The gain of rod phototransduction: reconciliation of biochemical and electrophysiological measurements. Neuron 27:525-537.

Lyubarsky AL, Chen C, Simon MI, Pugh Jr EN (2000) Mice lacking G-protein receptor kinase 1 have profoundly slowed recovery of conedriven retinal responses. J Neurosci 20:2209-2217.

Maeda T, Ohguro H, Sohma H, Kuroki Y, Wada H, Okisaka S, Murakami A (2000) Purification and characterization of bovine cone arrestin (cArr). FEBS Lett 470:336-340.

Mata NL, Radu RA, Clemmons RC, Travis GH (2002) Isomerization and oxidation of vitamin A in cone-dominant retinas: a novel pathway for visual-pigment regeneration in daylight. Neuron 36:69-80.

Mears AJ, Kondo M, Swain PK, Takada Y, Bush RA, Saunders TL, Sieving PA, Swaroop A (2001) Nrl is required for rod photoreceptor development. Nat Genet 29:447-452.

Mendez A, Burns ME, Roca A, Lem J, Wu LW, Simon MI, Baylor DA, Chen J (2000) Rapid and reproducible deactivation of rhodopsin requires multiple phosphorylation sites. Neuron 28:153-164.

Murakami A, Yajima T, Sakuma H, McLaren MJ, Inana G (1993) X-arrestin: a new retinal arrestin mapping to the $\mathrm{X}$ chromosome. FEBS Lett 334:203-209.

Perry RJ, McNaughton PA (1991) Response properties of cones from the retina of the tiger salamander. J Physiol (Lond) 433:561-587.

Pitcher JA, Freedman NJ, Lefkowitz RJ (1998) G-protein-coupled receptor kinases. Annu Rev Biochem 67:653-692.

Pugh Jr EN, Lamb TD (2000) Phototransduction in vertebrate rods and cones: molecular mechanisms of amplification, recovery and light adaptation. In: Handbook of biological physics, Vol 3 (Stavenga DG, DeGrip WJ, Pugh Jr EN, eds), pp 184-255. Amsterdam: Elsevier.

Rehemtulla A, Warwar R, Kumar R, Ji X, Zack DJ, Swaroop A (1996) The basic motif-leucine zipper transcription factor $\mathrm{Nrl}$ can positively regulate rhodopsin gene expression. Proc Natl Acad Sci USA 93:191-195.

Sakuma H, Inana G, Murakami A, Higashide T, McLaren MJ (1996) Immunolocalization of $\mathrm{X}$-arrestin in human cone photoreceptors. FEBS Lett 382:105-110.

Schnapf JL, Nunn BJ, Meister M, Baylor DA (1990) Visual transduction in cones of the monkey Macaca fascicularis. J Physiol (Lond) 427:681-713. 
Smith WC, Gurevich EV, Dugger DR, Vishnivetskiy SA, Shelamer CL, McDowell JH, Gurevich VV (2000) Cloning and functional characterization of salamander rod and cone arrestins. Invest Ophthalmol Vis Sci 41:2445-2455.

Swain PK, Hicks D, Mears AJ, Apel IJ, Smith JE, John SK, Hendrickson A, Milam AH, Swaroop A (2001) Multiple phosphorylated isoforms of NRL are expressed in rod photoreceptors. J Biol Chem 276:36824-36830.

Swaroop A, Xu JZ, Pawar H, Jackson A, Skolnick C, Agarwal N (1992) A conserved retina-specific gene encodes a basic motif/leucine zipper domain. Proc Natl Acad Sci USA 89:266-270.

Tachibanaki S, Tsushima S, Kawamura S (2001) Low amplification and fast visual pigment phosphorylation as mechanisms characterizing cone photoresponses. Proc Natl Acad Sci USA 98:14044-14049.

Tornehave D, Hougaard DM, Larsson L (2000) Microwaving for double indirect immunofluorescence with primary antibodies from the same species and for staining of mouse tissues with mouse monoclonal antibodies. Histochem Cell Biol 113:19-23.

Walter AE, Shuster TA, Farber DB (1986) Light-induced phosphorylation of proteins from the all-cone retina of the lizard, Anolis carolinensis. Invest Ophthalmol Vis Sci 27:1609-1614.

Weiss ER, Raman D, Shirakawa S, Ducceschi MH, Bertram PT, Wong F, Kraft TW, Osawa S (1998) The cloning of GRK7, a candidate cone opsin kinase, from cone- and rod-dominant mammalian retinas. Mol Vis 4:27.

Weiss ER, Ducceschi MH, Horner TJ, Li A, Craft CM, Osawa S (2001) Species-specific differences in expression of G-protein-coupled receptor kinase (GRK) 7 and GRK1 in mammalian cone photoreceptor cells: implications for cone cell phototransduction. J Neurosci 21:9175-9184.

Wilden U (1995) Duration and amplitude of the light-induced cGMP hydrolysis in vertebrate photoreceptors are regulated by multiple phosphorylation of rhodopsin and by arrestin binding. Biochemistry 34:1446-1454.
Wilden U, Kuhn H (1982) Light-dependent phosphorylation of rhodopsin: number of phosphorylation sites. Biochemistry 21:3014-3022.

Wilden U, Hall SW, Kuhn H (1986a) Phosphodiesterase activation by photoexcited rhodopsin is quenched when rhodopsin is phosphorylated and binds the intrinsic 48 -kDa protein of rod outer segments. Proc Natl Acad Sci USA 83:1174-1178

Wilden U, Wust E, Weyand I, Kuhn H (1986b) Rapid affinity purification of retinal arrestin ( $48 \mathrm{kDa}$ protein) via its light-dependent binding to phosphorylated rhodopsin. FEBS Lett 207:292-295.

Xu J, Dodd RL, Makino CL, Simon MI, Baylor DA, Chen J (1997) Prolonged photoresponses in transgenic mouse rods lacking arrestin. Nature 389:505-509.

Zhang Y, Li A, Zhu X, Wong CH, Brown B, Craft CM (2001) Cone arrestin expression and induction in retinoblastoma cells. In: Ninth international symposium on retinal degeneration (Anderson RE, LaVail MM, Hollyfield JG, eds), pp 309-317. Durango, CO: Kluwer Academic.

Zhao X, Huang J, Khani SC, Palczewski K (1998) Molecular forms of human rhodopsin kinase (GRK1). J Biol Chem 273:5124-5131.

Zhao X, Yokoyama K, Whitten ME, Huang J, Gelb MH, Palczewski K (1999) A novel form of rhodopsin kinase from chicken retina and pineal gland. FEBS Lett 454:115-121.

Zhu X, Craft CM (2000) Modulation of CRX transactivation activity by phosducin isoforms. Mol Cell Biol 20:5216-5226.

Zhu X, Ma B, Babu S, Murage J, Knox BE, Craft CM (2002a) Mouse cone arrestin gene characterization: promoter targets expression to cone photoreceptors. FEBS Lett 524:116-122.

Zhu X, Li A, Brown B, Weiss ER, Osawa S, Craft CM (2002b) Mouse cone arrestin expression pattern: light-induced translocation in cone photoreceptors. Mol Vis 8:462-471. 